Lawrence A. Silverman*, Xu Han, Huan Huang, Aimee M. Near and Yiqun Hu

\title{
Clinical characteristics and treatment patterns with histrelin acetate subcutaneous implants vs. leuprolide injections in children with precocious puberty: a real-world study using a US claims database
}

https://doi.org/10.1515/jpem-2020-0721

Received December 18, 2020; accepted April 12, 2021;

published online June 21, 2021

\section{Abstract}

Objectives: Gonadotropin-releasing hormone analogs are the treatment of choice for central precocious puberty (CPP). This study characterizes patients treated with histrelin implant or leuprolide injection.

Methods: A US claims database was used to identify patients aged $\leq 20$ years with $\geq 1$ histrelin or leuprolide claim (index treatment) between April 2010 and November 2017 and continuous enrollment $\geq 3$ months before and $\geq 12$ months after the index treatment date.

Results: Overall, 4,217 patients (histrelin, $n=1,001$; leuprolide, $n=3,216$ ) were identified. The percentage of patients with CPP diagnosis was greater in the histrelin $(96.5 \%)$ vs. leuprolide $(68.8 \%$; $<<0.0001)$ cohort. In patients with CPP (histrelin, $n=966$; leuprolide, $n=2,214$ ), mean age at treatment initiation was similar for histrelin $(9.0 \pm 2.0$ years $)$ and leuprolide $(9.1 \pm 2.3$ years $)$, with $>50 \%$ of patients aged 6-9 years. Mean treatment duration was significantly longer for histrelin $(26.7 \pm 14.8$ months $)$ vs. leuprolide (14.1 \pm 12.1 months; $\mathrm{p}<0.0001)$, and was longer in younger patient groups. More patients switched from leuprolide to histrelin (12.3\%) than vice versa $(3.6 \%$; $\mathrm{p}<0.0001)$. Median annual total treatment costs were slightly lower for the histrelin cohort $(\$ 23,071$ [interquartile

Xu Han and Huan Huang were employees of IQVIA at time the study was conducted.

*Corresponding author: Lawrence A. Silverman, MD, Division of Pediatric Endocrinology, Goryeb Children's Hospital Atlantic Health System, 100 Madison Avenue, Morristown, NJ, 07960, USA, Phone: 973 971 4340, E-mail: Lawrence.Silverman@atlantichealth.org Xu Han, Huan Huang and Aimee M. Near, IQVIA, Durham, NC, USA Yiqun Hu, Endo Pharmaceuticals Inc., Malvern, PA, USA range, $\$ 16,833-\$ 31,050]$ ) than the leuprolide cohort ( $\$ 27,021$ [interquartile range, $\$ 18,314-\$ 34,995] ; p<0.0001)$. Conclusions: Patients with CPP treated with histrelin had a longer duration of treatment, lower rates of index treatment discontinuation, and lower annual treatment costs vs. those treated with leuprolide.

Keywords: database; histrelin; leuprolide; LHRH; precocious puberty; receptors; Supprelin.

\section{Introduction}

Central precocious puberty (CPP) is defined as the premature appearance of secondary sexual characteristics ( $<8$ years in girls; $<9$ years in boys) caused by premature reactivation of the hypothalamic-pituitary-gonadal axis $[1,2]$. CPP is approximately 10 times more common in girls than boys and is most commonly idiopathic [3, 4]. If untreated, CPP can have marked effects on physical development, specifically reduced adult height secondary to early epiphyseal fusion [5]. In addition, early onset of puberty has been associated with psychological issues, including depression and anxiety [6-8].

Long-acting gonadotropin-releasing hormone ( $\mathrm{GnRH})$ analogs are the standard treatment for CPP; the goals of therapy include regression or stabilization of secondary sexual characteristics, return to normal prepubertal growth velocity, and bone-age advancement and preservation of adult height potential [9-11]. Commonly used GnRH analogs approved by the US Food and Drug Administration (FDA) for the treatment of CPP include histrelin acetate (Supprelin ${ }^{\circledR}$ LA; Endo Pharmaceuticals Inc., Malvern, PA), administered as a once-yearly subcutaneous implant [12, 13]; leuprolide acetate, administered as an intramuscular injection every 1 or 3 months (Lupron Depot-PED $^{\circledR}$; AbbVie Inc., North Chicago, IL) [14, 15]; triptorelin (Triptodur ${ }^{\circledR}$; Arbor Pharmaceuticals, LLC, Atlanta, GA), administered as an intramuscular injection 
every 24 weeks [16, 17]; and subcutaneous leuprolide acetate injectable suspension approved in 2020 by the FDA (Fensolvi ${ }^{\circledR}$; Tolmar Pharmaceuticals, Inc., Fort Collins, CO), which is administered every 6 months $[18,19]$.

Hormone suppression following treatment with these $\mathrm{GnRH}$ analogs is typically achieved within 1-2 months of initiating therapy and continues throughout treatment [13, 15, 20, 21]. Pubertal development resumes after discontinuation of the $\mathrm{GnRH}$ analog, and age at menarche for girls receiving the therapy is consistent with that for the general population [22-24]. Studies of long-term outcomes after GnRH treatment have found no associated adverse effects on reproductive potential and no increased risk for obesity, metabolic derangement, or malignancy in adulthood [25-29].

To date, there is limited longitudinal information regarding the pattern of use of GnRH analogs in a realworld setting. The objectives of the current study are to describe the characteristics of patients treated with histrelin implant or leuprolide injection and to compare treatment patterns and annual treatment costs for patients with CPP who have used these therapies.

\section{Materials and methods}

This retrospective study was conducted using the IQVIA PharMetrics ${ }^{\circledR}$ Plus health plan claims database and the Quest Diagnostics laboratory database. The claims database includes adjudicated health plan claims for $>150$ million individuals, has diverse US geographic representation, and encompasses the majority of US hospitals and healthcare providers. Information in the database includes demographics, diagnoses, inpatient and outpatient procedures, prescription dispensation, and payments. Data are available from 2006 onward, with a 5- to 6-month lag due to claims adjudication. The laboratory database, leveraged for a subset of analyses, includes approximately 3,500 laboratory tests and encompasses data from $>100$ million patients. The study databases were linked using a HIPAA-compliant methodology that has been described elsewhere [30, 31]. Study approval by an institutional review board or ethics committee and informed consent from patients were not necessary because this retrospective analysis used deidentified data obtained from secondary sources.

Patients aged $\leq 20$ years with $\geq 1$ claim in the PharMetrics Plus database for histrelin or leuprolide (index treatment) between April 1, 2010 and November 30, 2017 were eligible for inclusion (patients treated with triptorelin between June 30, 2017 and October 31, 2018 were not included in the analysis due to the limited number of patients [ $n=13]$ available at the time of study initiation). The date of the first claim for histrelin or leuprolide was defined as the index treatment date. Leuprolide injections with gonadotropin stimulation test on the same day were not included. Additional patient selection criteria are detailed in Figure 1. Briefly, patients were required to have $\geq 3$ months of continuous enrollment before the index date (baseline period) and $\geq 12$ months of continuous enrollment after the index date (follow-up period). Patients were excluded from the analysis if they had a diagnosis for prostate cancer, testicular cancer, endometriosis, or uterine leiomyomata during the baseline period, evidence of $>1 \mathrm{GnRH}$ analog (i.e., histrelin, leuprolide, triptorelin) on the index date, or lacked evidence of an implantation procedure (CPT 11981 or 11983) within 90 days after the index date for histrelin. The age limit was set at 20 years to provide a broad perspective on the use of GnRH analogs in children and adolescents. Because the overall cohort included patients with a range of diagnoses (e.g., gender identify disorder, short stature), a subcohort of patients with $\geq 1$ diagnosis of CPP during the baseline period or on index was identified based on International Classification of Diseases Ninth/Tenth Revision diagnosis codes (ICD-9: 259.1, 259.8, 259.9; ICD-10: E30.1, E22.8, E30.8). The subsequent cohort comparisons were made only among those patients with a CPP diagnosis code.

Patient demographics and clinical characteristics at baseline were compared for the histrelin and leuprolide cohorts for the overall analysis population and for a cohort of patients with $\geq 1 \mathrm{CPP}$ diagnosis in the claims database. In the CPP cohort, assessment of treatment patterns included number of implants/injections, treatment setting, treatment duration, concomitant treatment with growth hormone, rates of index treatment discontinuation and switch to another GnRH analog, and index and annual treatment costs. Treatment duration was defined as the time from index date to discontinuation of index treatment, switch to another GnRH analog, or end of follow-up, whichever occurred first. Discontinuation of histrelin was defined as implant removal (procedural code entry) without subsequent implant (no procedural code entry) on the same day or any time during the follow-up period; discontinuation of leuprolide was defined as a gap of $\geq 6$ months between injections. Age at discontinuation of index treatment was calculated as [(year of discontinuation date) - (birth year)].

Total annual cost was defined as the total treatment cost while on treatment, divided by duration of treatment (including index date). The total histrelin treatment cost included the medication, implantation and removal procedures (including surgeon time), anesthesia, imaging, and office visits. The total leuprolide treatment cost included medication, injection procedures, and office visits.

An exploratory subgroup analysis of hormone levels (i.e., luteinizing hormone [LH], follicle-stimulating hormone [FSH], estradiol [females], and testosterone [males]) was conducted for patients with CPP who had data linked to the Quest database. The data distributions were evaluated, and hormone levels greater than the 95th percentile of the corresponding distribution were excluded from the analysis to eliminate values that were nonphysiological and considered the result of data entry errors. Mean hormone levels during the baseline and follow-up periods were evaluated, as was hormone suppression during treated follow-up. Hormone suppression was defined as postindex measurements during treated follow-up with values $<4 \mathrm{mIU} / \mathrm{mL}$ (LH), $<2.5 \mathrm{mIU} / \mathrm{mL}$ (FSH), $<20 \mathrm{pg} / \mathrm{mL}$ (estradiol), and $<30 \mathrm{ng} / \mathrm{dL}$ (testosterone).

Statistical analyses were performed using SAS version 9.4 software (SAS Institute, Inc., Cary, NC). Data are mean \pm standard deviation, unless otherwise indicated. Patient characteristics, treatment patterns and costs were compared for histrelin vs. leuprolide using t-tests or Wilcoxon rank sum tests for continuous variables (depending on the normality of the data distribution) and chi-square or Fisher's exact tests for categorical variables. All comparisons were conducted assuming a two-tailed test of significance and type I error rate of 0.05 . 


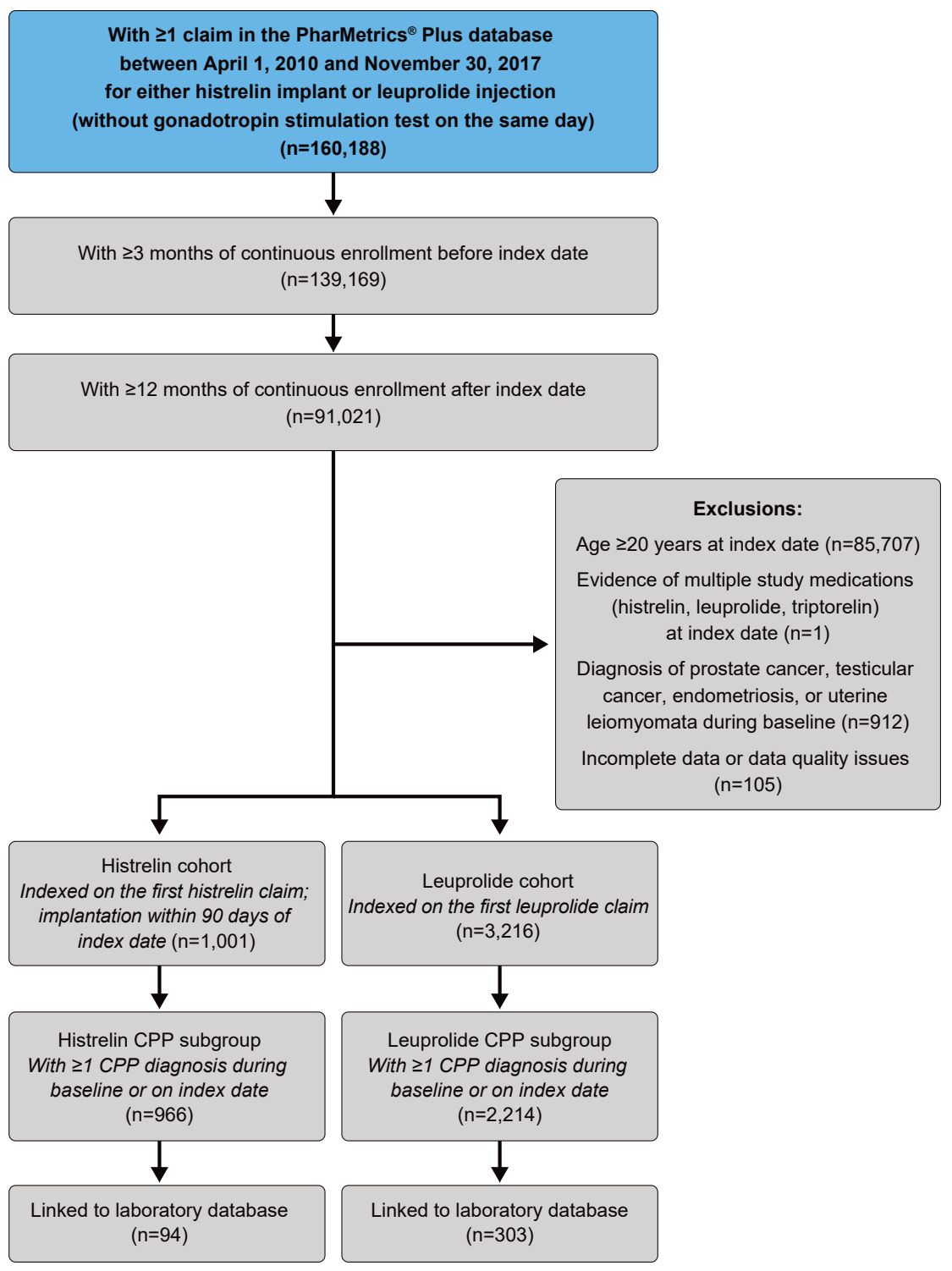

Figure 1: Patient selection. CPP, central precocious puberty.

\section{Results}

A total of 1,001 patients had $\geq 1$ claim for histrelin implant and 3,216 patients had $\geq 1$ claim for leuprolide injection (Figure 1, Table 1). Most patients were female (histrelin, $80.8 \%$; leuprolide, $78.5 \% ; \mathrm{p}=0.12$ ). The majority of patients were 6-12 years old at the index date (histrelin, 91.0\%; leuprolide, 68.4\%); the overall mean age at index was lower in the histrelin cohort ( $9.1 \pm 2.2$ years) compared with the leuprolide cohort $(10.9 \pm 3.9$ years; $\mathrm{p}<0.0001)$. More patients in the histrelin cohort had a CPP diagnosis compared with those in the leuprolide cohort ( 96.5 vs. $68.8 \%$, respectively; $\mathrm{p}<0.0001)$. The remaining patients in the leuprolide cohort were diagnosed with other conditions (e.g., gender identity disorder).

\section{Patients with central precocious puberty}

Among patients with a CPP diagnosis, the histrelin $(\mathrm{n}=966)$ and leuprolide $(n=2,214)$ cohorts were predominantly female (82.1 and $79.0 \%$, respectively; $\mathrm{p}=0.04)$; mean age was similar $(9.0 \pm 2.0$ years and $9.1 \pm 2.3$ years, respectively; $\mathrm{p}=0.09$ ); and almost all patients (96.8 and 93.9\%, respectively) were $<13$ years old. In both CPP cohorts, the mean age was younger in girls than boys (Table 1). A small percentage of patients in each CPP cohort (histrelin, 6.8\%; leuprolide, $5.2 \% ; \mathrm{p}=0.06$ ) had a mean history of growth hormone treatment during the baseline period of more than 2 years.

In the histrelin CPP cohort, 688 patients (71.2\%) received the index implant as their initial implant and 
Table 1: Baseline patient demographics and clinical characteristics.

\begin{tabular}{|c|c|c|c|c|c|c|}
\hline \multirow[t]{2}{*}{ Characteristic } & \multicolumn{3}{|c|}{ Overall cohort } & \multicolumn{3}{|c|}{ CPP subgroup } \\
\hline & Histrelin $(n=1,001)$ & Leuprolide $(n=3,216)$ & p-Value & Histrelin $(n=966)$ & Leuprolide $(n=2,214)$ & p-Value \\
\hline \multicolumn{7}{|l|}{ Sex, n (\%) } \\
\hline Male & $192(19.2)$ & $691(21.5)$ & 0.12 & $173(17.9)$ & $466(21.0)$ & 0.04 \\
\hline Female & $809(80.8)$ & $2,525(78.5)$ & & $793(82.1)$ & $1,748(79.0)$ & \\
\hline \multicolumn{7}{|l|}{ Age, $y$, mean (SD) } \\
\hline Total & $9.1(2.2)$ & $10.9(3.9)$ & $<0.0001$ & $9.0(2.0)$ & $9.1(2.3)$ & 0.09 \\
\hline Male & $10.9(2.3)$ & $11.4(3.1)$ & 0.04 & $10.6(2.1)$ & $10.7(2.4)$ & 0.63 \\
\hline Female & $8.7(1.9)$ & $10.8(4.1)$ & $<0.0001$ & $8.7(1.8)$ & $8.7(2.0)$ & 0.36 \\
\hline \multicolumn{7}{|l|}{ Age group, n (\%) } \\
\hline$\leq 5 \mathrm{y}$ & 39 (3.9) & $135(4.2)$ & $<0.0001$ & $39(4.0)$ & $110(5.0)$ & 0.008 \\
\hline $6-9 y$ & $543(54.2)$ & $1,299(40.4)$ & & $543(56.2)$ & $1,229(55.5)$ & \\
\hline $10-12 y$ & $368(36.8)$ & $901(28.0)$ & & $353(36.5)$ & $741(33.5)$ & \\
\hline $13-15 y$ & $39(3.9)$ & $379(11.8)$ & & $26(2.7)$ & $111(5.0)$ & \\
\hline $16-20 y$ & $12(1.2)$ & $502(15.6)$ & & $5(0.5)$ & $23(1.0)$ & \\
\hline Age group, males, n (\%) & $\mathrm{n}=192$ & $n=691$ & & $n=173$ & $\mathrm{n}=466$ & \\
\hline$\leq 5 \mathrm{y}$ & $3(1.6)$ & $25(3.6)$ & 0.002 & $3(1.7)$ & $12(2.6)$ & 0.23 \\
\hline $6-9 y$ & $37(19.3)$ & $140(20.3)$ & & $37(21.4)$ & $123(26.4)$ & \\
\hline $10-12$ y & $116(60.4)$ & $312(45.2)$ & & $111(64.2)$ & $251(53.9)$ & \\
\hline $13-15$ y & $26(13.5)$ & $147(21.3)$ & & $18(10.4)$ & $64(13.7)$ & \\
\hline $16-20 y$ & $10(5.2)$ & $67(9.7)$ & & $4(2.3)$ & $16(3.4)$ & \\
\hline Age group, females, $n(\%)$ & $\mathrm{n}=809$ & $n=2,525$ & & $n=793$ & $n=1,748$ & \\
\hline$\leq 5 \mathrm{y}$ & $36(4.4)$ & $110(4.4)$ & $<0.0001$ & $36(4.5)$ & $98(5.6)$ & 0.03 \\
\hline $6-9 y$ & $506(62.5)$ & $1,159(45.9)$ & & $506(63.8)$ & $1,106(63.3)$ & \\
\hline $10-12$ y & $252(31.1)$ & $589(23.3)$ & & $242(30.5)$ & $490(28.0)$ & \\
\hline $13-15$ y & $13(1.6)$ & $232(9.2)$ & & $8(1.0)$ & $47(2.7)$ & \\
\hline $16-20 y$ & $2(0.2)$ & $435(17.2)$ & & $1(0.1)$ & $7(0.4)$ & \\
\hline \multicolumn{7}{|l|}{ Payer type, n (\%) } \\
\hline Commercial & $577(57.6)$ & $1,865(58.0)$ & $<0.0001$ & $558(57.8)$ & $1,264(57.1)$ & $<0.0001$ \\
\hline Medicaid & $45(4.5)$ & $335(10.4)$ & & $43(4.5)$ & $253(11.4)$ & \\
\hline Self-insured & $374(37.4)$ & $1,001(31.1)$ & & $360(37.3)$ & $687(31.0)$ & \\
\hline Other/unknown & $5(0.5)$ & $15(0.5)$ & & $5(0.5)$ & $10(0.5)$ & \\
\hline \multicolumn{7}{|l|}{ Comorbidities, n (\%) } \\
\hline Anxiety & $323(32.3)$ & $997(31.0)$ & 0.45 & $290(30.0)$ & $530(23.9)$ & 0.0003 \\
\hline CNS abnormalities & $129(12.9)$ & $386(12.0)$ & 0.46 & $127(13.1)$ & $247(11.2)$ & 0.11 \\
\hline Depression & $224(22.4)$ & $700(21.8)$ & 0.68 & $195(20.2)$ & $315(14.2)$ & $<0.0001$ \\
\hline GH deficiency & $50(5.0)$ & $197(6.1)$ & 0.18 & $46(4.8)$ & $143(6.5)$ & 0.06 \\
\hline
\end{tabular}

CNS, central nervous system; CPP, central precocious puberty; GH, growth hormone; SD, standard deviation.

$278(28.8 \%)$ patients received the index implant as a subsequent implant. Histrelin implantation was usually performed in an outpatient setting $(78.2 \%[n=755])$, physician office $(24.7 \%$ [ $n=239])$, or ambulatory surgical center $(5.9 \%[\mathrm{n}=57])$. In the overall leuprolide cohort, the most common settings for the index medication claim were pharmacy $(55.5 \%[n=1,784])$, healthcare provider office (25.2\% [ $n=811])$, outpatient hospital (11.3\% [n=362]), or unknown $(8.1 \%[n=261])$. Among 1,414 patients in the leuprolide CPP cohort with index dosing information, the most common prescribed doses were $7.5 \mathrm{mg}(29.5 \%$ [ $\mathrm{n}=417]), 11.25 \mathrm{mg}(30.1 \%$ [ $\mathrm{n}=425]), 15.0 \mathrm{mg}(15.2 \%$ [n=215]), and $30.0 \mathrm{mg}(19.0 \%[\mathrm{n}=268])$. According to the US prescribing information, a leuprolide dose of $7.5 \mathrm{mg}$ or $15.0 \mathrm{mg}$ is approved for a 1-month administration schedule, $30.0 \mathrm{mg}$ for a 3-month administration schedule, and $11.25 \mathrm{mg}$ may be prescribed for either a 1-month or 3-month administration schedule [14].

Mean duration of the post-treatment follow-up period (after initiation of index treatment) was $40.0 \pm 24.4$ months in the histrelin cohort and $40.8 \pm 25.0$ months in the leuprolide cohort $(\mathrm{p}=0.36)$. The mean number of histrelin implants (including the index implant) was $1.9 \pm 0.9$ (range, 1-7), and the mean number of leuprolide injections was $11.0 \pm 11.0$ (range, $1-90)(\mathrm{p}<0.0001)$. Most of the 966 patients in the histrelin CPP cohort had one $(40.1 \%$ [n=387]) or two 
(40.9\% [ $\mathrm{n}=395]$ ) implants; the median number of injections in the leuprolide cohort was 7 (interquartile range, 4-15). The mean duration of treatment was significantly longer for the histrelin cohort ( $26.7 \pm 14.8$ months) compared with the leuprolide cohort (14.1 \pm 12.1 months; $\mathrm{p}<0.0001)$. When stratified by age at index treatment, younger patients had more implants or injections (Figure 2) and correspondingly longer treatment duration (Figure 3) in both treatment cohorts. The mean duration of a single histrelin implant was $14.3 \pm 4.2$ months (range, 0.3-46.7 months), and the mean time between placement of consecutive implants during follow-up was $13.7 \pm 3.3$ months (range, 1.0-56.1, months). Mean time between consecutive leuprolide injections was $1.5 \pm 1.3$ months (median, 1.0; range, 0.0-32.9). Concomitant treatment with growth hormone was reported for 9.1\% (88/966) of patients in the histrelin cohort vs. $6.7 \%$ $(148 / 2,214)$ of patients in the leuprolide cohort $(\mathrm{p}=0.02)$.

Fewer patients discontinued index treatment in the histrelin cohort (i.e., implant removal without subsequent implant) than the leuprolide cohort (defined as a gap of $\geq 6$ months between injections) before the end of follow-up
(49.5\% [478/966] vs. $75.1 \%$ [1,662/2,214], respectively; $\mathrm{p}<0.0001$ ), and the mean age at index treatment discontinuation was significantly higher for histrelin vs. leuprolide (11.6 \pm 1.5 years vs. $10.2 \pm 2.4$ years, respectively; $\mathrm{p}<0.0001)$. For 484 patients with final histrelin implant removal information, the most common settings for removal were similar to those for initial insertion (outpatient hospital, 76.8\%; and healthcare provider office, $27.5 \%$ ). The use of imaging procedures (e.g., magnetic resonance imaging, ultrasound) was rarely observed for histrelin implant removal (2.2\%). Among patients who discontinued index treatment, 3.6\% (17/478) of patients in the histrelin cohort were switched to leuprolide and $12.3 \%$ $(205 / 1,662)$ of patients in the leuprolide cohort were switched to histrelin $(\mathrm{p}<0.0001)$.

Mean annual treatment costs were slightly lower in the histrelin cohort vs. the leuprolide cohort $(\$ 27,186 \pm \$ 24,724$ vs. $\$ 29,258 \pm \$ 20,013$, respectively; $p=0.01$ [Table 2]). Similarly, median (range) annual treatment costs were lower for histrelin $(\$ 23,071$ [\$48-\$575,169]) vs. leuprolide $(\$ 27,021$ [ $\$ 0-\$ 187,724] ; \mathrm{p}<0.0001)$. Histrelin medication

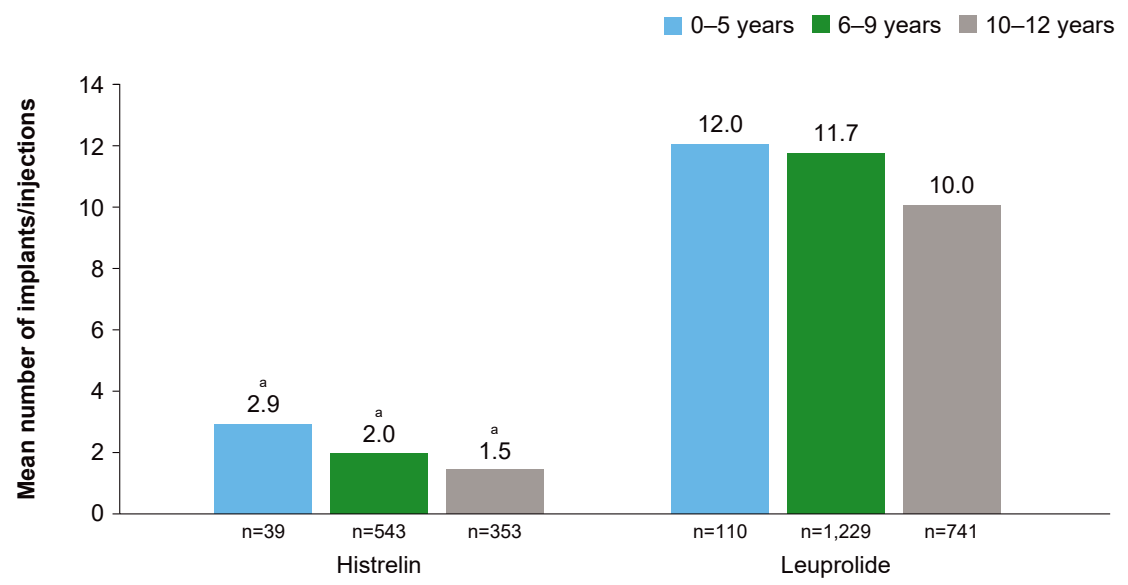

0-5 years $\square-6$ years $\square 10-12$ years

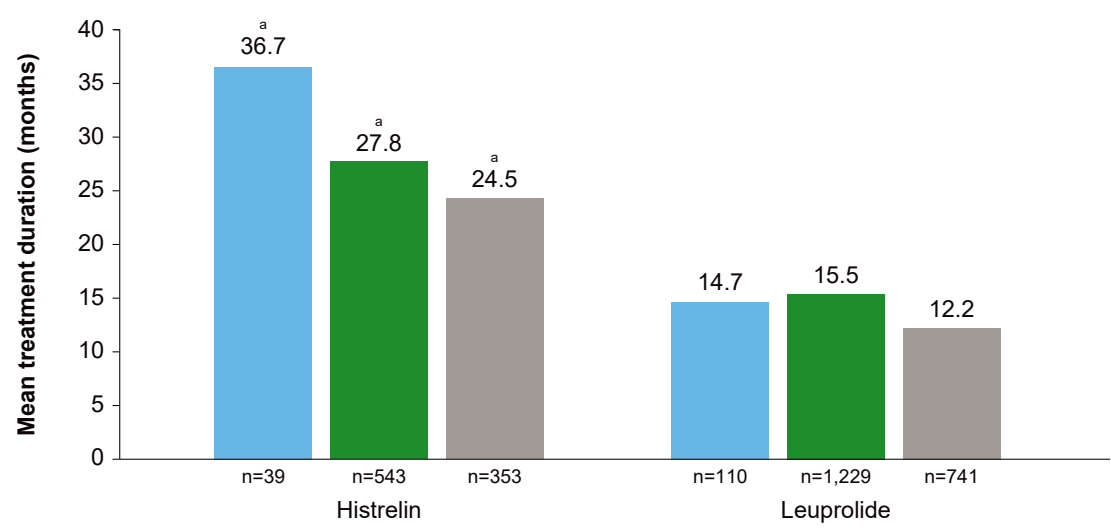

Figure 2: Mean number of histrelin implants or leuprolide injections in patients with CPP, stratified by age ( $\leq 12$ years). ${ }^{a} p<0.0001$ for histrelin vs. leuprolide. CPP, central precocious puberty.
Figure 3: Mean treatment duration with histrelin or leuprolide in patients with CPP, stratified by age ( $\leq 12$ years).

${ }^{a} p<0.0001$ for histrelin vs. leuprolide. CPP, central precocious puberty. 
Table 2: Treatment costs (CPP subgroup).

\begin{tabular}{|c|c|c|c|}
\hline Parameter & Histrelin $(n=966)$ & Leuprolide $(n=2,214)$ & p-Value \\
\hline \multicolumn{4}{|c|}{ Cost per histrelin index implant/subsequent implant ${ }^{\mathrm{a}}$} \\
\hline Mean (SD) & $\$ 28,379(\$ 19,804)$ & - & \\
\hline Median (IQR) & $\$ 25,225(\$ 20,220-\$ 31,078)$ & & \\
\hline Minimum-maximum & $\$ 185-\$ 217,531$ & & \\
\hline \multicolumn{4}{|c|}{ Cost of final implant removal ${ }^{\mathrm{b}}$} \\
\hline Mean (SD) & $\$ 2,620(\$ 3,667)$ & - & \\
\hline Median (IQR) & $\$ 1,377(\$ 550-\$ 3,618)$ & & \\
\hline Minimum-maximum & $\$ 53-\$ 48,778$ & & \\
\hline \multicolumn{4}{|c|}{ Cost of leuprolide, per injection ${ }^{c}$} \\
\hline Mean (SD) & - & $\$ 3,696(\$ 2,743)$ & \\
\hline Median (IQR) & & $\$ 2,588(\$ 1,723-\$ 5,986)$ & \\
\hline Minimum-maximum & & $\$ 0-\$ 19,314$ & \\
\hline \multicolumn{4}{|c|}{ Total treatment cost PPPY during treatment period ${ }^{d}$} \\
\hline Mean (SD) & $\$ 27,186(\$ 24,724)$ & $\$ 29,258(\$ 20,013)$ & 0.01 \\
\hline Median (IQR) & $\$ 23,071(\$ 16,883-\$ 31,050)$ & $\$ 27,021(\$ 18,314-\$ 34,995)$ & $<0.0001$ \\
\hline Minimum-maximum & $\$ 48-\$ 575,169$ & $\$ 0-\$ 187,724$ & - \\
\hline
\end{tabular}

${ }^{a}$ The cost of each insertion procedure (including the index implantation) among patients with $\geq 1$ postindex implantation; includes costs for the implant, initial implantation, removal and subsequent implantation, anesthesia, imaging, and other costs (e.g., office consultation, outpatient visit evaluation). ${ }^{\mathrm{b}} \mathrm{Among}$ patients with final implant removal; includes costs for removal, anesthesia, imaging, and other costs (e.g., office consultation, outpatient visit evaluation). ' Includes costs for leuprolide, injection procedure, and office visit. ${ }^{\mathrm{d}}$ Total treatment cost while on treatment divided by duration of treatment (including index date); histrelin treatment cost includes total cost of first (index) implantation, total cost of postindex implantations, and cost of final implant removal. CPP, central precocious puberty; IQR, interquartile range; PPPY, per patient per year; SD, standard deviation.

(the implant) accounted for $85.9 \%$ of the total annual treatment cost. The mean cost of leuprolide per injection was $\$ 3,696 \pm \$ 2,743$.

A relatively small number of patients with CPP (histrelin, $n=94$; leuprolide, $n=303$ ) had laboratory data available for an exploratory analysis of hormone levels. Mean hormone levels were lower during the treated follow-up period compared with baseline in both cohorts and for all primary and secondary sexual hormones (LH, $\mathrm{FSH}$, estradiol in girls, testosterone in boys), except for $\mathrm{LH}$ in boys. Mean on-treatment hormone levels were below the suppression threshold for each hormone in both cohorts, except for testosterone in leuprolide-treated boys. In this small sample, testosterone suppression during treated follow-up was observed in $86.4 \%(19 / 22)$ of boys treated with histrelin and $68.8 \%$ (33/48) of boys treated with leuprolide. LH levels were suppressed in all boys $(100 \%$, $2 / 2)$ and all girls $(100 \%, 7 / 7)$ who were maintained on histrelin implant, and in $72.7 \%$ of boys (8/11) and $94.9 \%$ of girls (37/39) maintained on leuprolide injections. FSH levels were suppressed in all observed girls on histrelin $(100 \%, 7 / 7)$ and $61.8 \%$ (21/34) of girls on leuprolide; and estradiol levels were suppressed in all girls on histrelin
$(100 \%, 5 / 5)$ and $78.6 \%(11 / 14)$ on leuprolide during treated follow-up. After discontinuation of treatment, mean hormone levels were similar to those observed at baseline.

\section{Discussion}

This retrospective database analysis is among the first real-world studies to evaluate the patient characteristics, treatment patterns, and costs associated with GnRH analog treatment using histrelin implant or leuprolide injection. Overall, histrelin claims identified for the study were used almost exclusively for the treatment of patients with CPP, whereas leuprolide was also prescribed for a variety of other conditions including gender identity disorder. Analyses using the Pediatric Health Information System database, which includes $>6$ million patients in 43 US children's hospitals, have reported a substantial increase from 2013 to 2016 in the off-label use of GnRH analogs [32], including increased use of histrelin (from 2004 to 2016) for patients receiving transgender-related treatments [33].

In patients with $\mathrm{CPP}$, the analysis indicated that treatment was generally initiated between 6 and 12 years of 
age (mean age, 9 years). Given the known benefits of early initiation of GnRH analog therapy for CPP, particularly the greater effect on final adult height when treatment is started before age 8 years $[34,35]$, timing of treatment initiation may have been suboptimal for some patients in the study population. The mean age of 9 years at treatment initiation also suggests use of $\mathrm{GnRH}$ analogs in children (particularly girls) with mildly early but not truly precocious puberty, as has been reported previously [36]. The longer mean duration of treatment observed in the current analysis for histrelin (27 months) compared with leuprolide (14 months) is notable because CPP treatment for $<1.5$ years is unlikely to achieve the desired outcomes in increasing final height, although it may have psychological benefits by delaying onset of menarche to 10 years of age or older. Insurance coverage typically requires a duration of at least 1 year and 1 day between histrelin implantations; however, a prospective observational study conducted in a clinical setting found that a single implant left in place was effective for 24 months [37]. This approach could reduce the number of procedures and associated costs for treatment of CPP with histrelin [24, 37] and also increase patient convenience.

With regard to treatment patterns, the lower rate of index treatment discontinuation observed with histrelin relative to leuprolide was consistent with the use of a once-yearly histrelin implant compared with a leuprolide injection administered monthly or quarterly. The mean time between leuprolide injections (1.5 months) suggests that most patients in the leuprolide cohort received the once-monthly administered formulation. The mean time between histrelin implants (13.7 months) was consistent with findings from a retrospective observational study of histrelin implantation (2008-2017) in a single pediatric care center [38]. Mean age of discontinuation for histrelin treatment in the current study (11.6 years) was consistent with the US prescribing recommendation for patients with CPP [12].

A previously published retrospective claims analysis of patients with CPP reported that healthcare costs were similar for patients treated with histrelin or leuprolide [39]. That study differed from the current study in several aspects, including the patient population and outcomes assessed. The prior study identified commercially insured and Medicaid patients $\leq 12$ years of age who had a diagnosis of CPP (based on one ICD-9 code [259.1]) between January 2010 and September 2014 and a claim for histrelin or leuprolide [39], whereas the current study used a database representative of the commercially insured population, included patients with an older maximum age ( $\leq 20$ years), identified CPP based on multiple diagnostic codes, and used a longer eligibility window (April 2010 through November 2017). Mean age at treatment onset was younger in the prior study (7.6-8.5 years) compared with the current study (9.1-9.2 years), presumably because of the more restricted age range [39]. The prior study found a considerably shorter mean duration of treatment with histrelin in commercially insured patients (14.2 months) compared with CPP cohort in the current study (26.7 months), which is likely related to the shorter mean duration of follow-up (29 months in the previous study vs. 40 months in the current study) and variations in the definition of treatment discontinuation. All-cause healthcare costs were reported in the prior study, whereas the current study focused on CPP treatment costs, thereby confounding a direct cost comparison between the two studies.

The current study included a small number of patients with hormone measurements during the study period. Because patients treated with a $\mathrm{GnRH}$ analogue during the baseline period were included along with treatment-naïve patients, some patients demonstrated hormone suppression before the index treatment. The mean levels for gonadotropins and sex steroids were suppressed during treatment, consistent with previously described data on long-term GnRH analog therapy [24]. Hormone levels rebounded after discontinuation of index treatment, indicating appropriate reactivation of the hypothalamicpituitary-gonadal axis. Additional studies with a larger sample size are warranted to evaluate these preliminary findings.

A limitation of the current study is that data availability was restricted to information captured in an administrative claims database, which may not fully represent treatment patterns and medical costs. For example, the cost of a leuprolide claim, as captured in this analysis, included bundled costs for medication, injection procedure, and office visit, and individual components could not be analyzed. Also, not all dose and formulation data on leuprolide were reported in the claims database; this limited the feasibility of conducting additional analysis for the user pattern and effect of different types of leuprolide (i.e., monthly injection vs. 3-month depot injection). The study included newly treated or previously treated patients, which may have confounded the assessment of treatment patterns, especially treatment duration, as well as changes in hormone levels. Information is lacking with regard to decisions made clinically, including duration of therapy, and future research is warranted to evaluate reasons for CPP treatment decisions and changes. Because the study population was primarily commercially insured, findings may not be generalizable to patients with other types of insurance (e.g., Medicaid). The 3-month 
formulation of leuprolide was approved by the FDA in August $2011 \quad(\sim 16$ months into the patient selection window) and the 6-month formulation was unavailable during the study period, so findings may not fully reflect current practice. Although not an objective of this study, given the trend in the earlier age of puberty onset, there is debate on whether the age for defining CPP should be reconsidered [36]. Lastly, the laboratory data entries did not include information on sample collection procedures (i.e., hormone level associated with stimulation test or random hormone level) and, because of the limited number of patients linked to laboratory data and because only a limited number of hormone measurements over time were available among these patients, it was not possible to evaluate intra-patient changes in hormone levels. Further research, adequately powered to detect changes in hormone levels, is warranted.

\section{Conclusions}

In this US retrospective claims database analysis, patients with CPP who were treated with histrelin generally had a longer treatment duration, lower discontinuation rate, and lower annual treatment costs than patients treated with leuprolide. Overall, these findings support the use of histrelin as an effective option for the ongoing management of patients with CPP.

Acknowledgments: Programming support for statistical analyses was provided by Yi-Chien Lee, MSc, IQVIA, Durham, NC, with funding from Endo Pharmaceuticals Inc. Technical editorial and medical writing assistance were provided, under the direction of the authors, by Mary Beth Moncrief, $\mathrm{PhD}$, and Nancy Holland, PhD, Synchrony Medical Communications, LLC, West Chester, PA. Funding for this assistance was provided by Endo Pharmaceuticals Inc.

Research funding: Funding for this study was provided by Endo Pharmaceuticals Inc., Malvern, PA.

Author contributions: All authors have accepted responsibility for the entire content of this manuscript and approved its submission.

Competing interests: Employment or leadership: Aimee Near is an employee of IQVIA, which conducted this analysis with funding from Endo Pharmaceuticals Inc. Xu Han and Huan Huang are former employees of IQVIA. Yiqun $\mathrm{Hu}$ is an employee of Endo Pharmaceuticals Inc. Honoraria: Lawrence Silverman reports receiving grant/ research support from Endo Pharmaceuticals Inc. and
Pfizer; serving as a consultant for AbbVie Inc., Endo Pharmaceuticals Inc., and Pfizer; serving on the speakers bureau for Endo Pharmaceuticals Inc.; and serving as an advisor and Data and Safety Monitoring Board member for Tolmar Pharmaceuticals, Inc.

Informed consent: Not applicable.

Ethical approval: Not applicable; study approval by an institutional review board or ethics committee was not necessary because this retrospective analysis used deidentified data obtained from secondary sources.

\section{References}

1. Carel JC, Léger J. Precocious puberty. N Engl J Med 2008;358: 2366-77.

2. Nebesio TD, Eugster EA. Current concepts in normal and abnormal puberty. Curr Probl Pediatr Adolesc Health Care 2007; 37:50-72.

3. Partsch CJ, Sippell WG. Pathogenesis and epidemiology of precocious puberty. Effects of exogenous oestrogens. Hum Reprod Update 2001;7:292-302.

4. Soriano-Guillén L, Corripio R, Labarta JI, Canete R, Castro-Feijoo L, Espino R, et al. Central precocious puberty in children living in Spain: incidence, prevalence, and influence of adoption and immigration. J Clin Endocrinol Metab 2010;95:4305-13.

5. Carel JC, Lahlou N, Roger M, Chaussain JL. Precocious puberty and statural growth. Hum Reprod Update 2004;10:135-47.

6. Stice E, Presnell K, Bearman SK. Relation of early menarche to depression, eating disorders, substance abuse, and comorbid psychopathology among adolescent girls. Dev Psychol 2001;37: 608-19.

7. Mendle J, Ryan RM, McKone KMP. Age at menarche, depression, and antisocial behavior in adulthood. Pediatrics 2018;141: e20171703.

8. Reardon LE, Leen-Feldner EW, Hayward C. A critical review of the empirical literature on the relation between anxiety and puberty. Clin Psychol Rev 2009;29:1-23.

9. Latronico AC, Brito VN, Carel J-C. Causes, diagnosis, and treatment of central precocious puberty. Lancet Diabetes Endocrinol 2016;4:265-74.

10. Carel JC, Eugster EA, Rogol A, Ghizzoni L, Palmert MR, ESPE-LWPES GnRH Analogs Consensus Conference Group, et al. Consensus statement on the use of gonadotropin-releasing hormone analogs in children. Pediatrics 2009;123:e752-62.

11. Kaplowitz P, Bloch C. Section on Endocrinology of the American Academy of Pediatrics. Evaluation and referral of children with signs of early puberty. Pediatrics 2016;137:e20153732.

12. Supprelin LA (histrelin acetate) subcutaneous implant. Malvern, PA: Endo Pharmaceuticals Inc; 2019.

13. Eugster EA, Clarke W, Kletter GB, Lee PA, Neely EK, Reiter EO, et al. Efficacy and safety of histrelin subdermal implant in children with central precocious puberty: a multicenter trial. J Clin Endocrinol Metab 2007;92:1697-704.

14. Lupron Depot-PED (leuprolide acetate for depot suspension) injection, powder, lyophilized, for suspension. North Chicago, IL: AbbVie Inc.; 2020. 
15. Carel JC, Lahlou N, Jaramillo O, Montauban V, Teinturier C, Colle $M$, et al. Treatment of central precocious puberty by subcutaneous injections of leuprorelin 3-month depot (11.25 mg). J Clin Endocrinol Metab 2002;87:4111-6.

16. Triptodur (triptorelin) for extended-release injectable suspension, for intramuscular use. Atlanta, GA: Arbor Pharmaceuticals, LLC; 2018.

17. Klein K, Yang J, Aisenberg J, Wright N, Kaplowitz P, Lahlou N, et al. Efficacy and safety of triptorelin 6-month formulation in patients with central precocious puberty. J Pediatr Endocrinol Metab 2016; 29:1241-8.

18. Fensolvi (leuprolide acetate) for injectable suspension, for subcutaneous use. Fort Collins, CO: Tolmar Pharmaceuticals, Inc.; 2020.

19. Klein KO, Freire A, Gryngarten MG, Kletter GB, Benson M, Miller BS, et al. Phase 3 trial of a small-volume subcutaneous 6-month duration leuprolide acetate treatment for central precocious puberty. J Clin Endocrinol Metab 2020;105:1-12.

20. Rahhal S, Clarke WL, Kletter GB, Lee PA, Neely EK, Reiter EO, et al. Results of a second year of therapy with the 12-month histrelin implant for the treatment of central precocious puberty. Int J Pediatr Endocrinol 2009;2009:812517.

21. Neely EK, Lee PA, Bloch CA, Larsen L, Yang D, Mattia-Goldberg C, et al. Leuprolide acetate 1-month depot for central precocious puberty: hormonal suppression and recovery. Int J Pediatr Endocrinol 2010;2010:398639.

22. Gillis D, Karavani G, Hirsch HJ, Strich D. Time to menarche and final height after histrelin implant treatment for central precocious puberty. J Pediatr 2013;163:532-6.

23. Fisher MM, Lemay D, Eugster EA. Resumption of puberty in girls and boys following removal of the histrelin implant. J Pediatr 2014;164:912-6 e1.

24. Silverman LA, Neely EK, Kletter GB, Lewis K, Chitra S, Terleckyj O, et al. Long-term continuous suppression with once-yearly histrelin subcutaneous implants for the treatment of central precocious puberty: a final report of a phase 3 multicenter trial. ) Clin Endocrinol Metab 2015;100:2354-63.

25. Heger S, Müller M, Ranke M, Schwarz HP, Waldhauser F, Partsch C), et al. Long-term GnRH agonist treatment for female central precocious puberty does not impair reproductive function. Mol Cell Endocrinol 2006;254-255:217-20.

26. Lazar L, Meyerovitch J, de Vries L, Phillip M, Lebenthal Y. Treated and untreated women with idiopathic precocious puberty: longterm follow-up and reproductive outcome between the third and fifth decades. Clin Endocrinol (Oxf) 2014;80:570-6.

27. Lazar L, Lebenthal Y, Yackobovitch-Gavan M, Shalitin S, de Vries L, Phillip M, et al. Treated and untreated women with idiopathic precocious puberty: $\mathrm{BMI}$ evolution, metabolic outcome, and general health between third and fifth decades. J Clin Endocrinol Metab 2015;100:1445-51.

28. Guaraldi F, Beccuti G, Gori D, Ghizzoni L. Management of endocrine disease: long-term outcomes of the treatment of central precocious puberty. Eur J Endocrinol 2016;174:R79-87.

29. Thornton P, Silverman LA, Geffner ME, Neely EK, Gould E, Danoff TM. Review of outcomes after cessation of gonadotropinreleasing hormone agonist treatment of girls with precocious puberty. Pediatr Endocrinol Rev 2014;11:306-17.

30. Zubeldia K, Romney GW. Anonymously linking a plurality of data records. US patent US6397224B1, 2002. https:// patents.google.com/patent/US6397224B1/en [Accessed 8 Feb 2021].

31. Ober NS, Grubmuller J, Farrell M, Wentworth C, Gilbert T, Barrett K, et al. System and method for generating de-identified health care data. US patent US7376677B2, 2008. https://patents.google. com/patent/US7376677B2/en?oq=US7376677B2 [Accessed 8 Feb 2021].

32. Lopez CM, Solomon D, Boulware SD, Christison-Lagay E. Trends in the "off-label" use of GnRH agonists among pediatric patients in the United States. Clin Pediatr (Phila) 2018;57:1432-5.

33. Lopez CM, Solomon D, Boulware SD, Christison-Lagay ER. Trends in the use of puberty blockers among transgender children in the United States. J Pediatr Endocrinol Metab 2018; 31:665-70.

34. Klein KO, Barnes KM, Jones JV, Feuillan PP, Cutler Jr. GB. Increased final height in precocious puberty after long-term treatment with LHRH agonists: the National Institutes of Health experience. J Clin Endocrinol Metab 2001;86:4711-6.

35. Eugster EA. Treatment of central precocious puberty. J Endocr Soc 2019;3:965-72.

36. Kaplowitz PB, Backeljauw PF, Allen DB. Toward more targeted and cost-effective gonadotropin-releasing hormone analog treatment in girls with central precocious puberty. Horm Res Paediatr 2018; 90:1-7.

37. Lewis KA, Goldyn AK, West KW, Eugster EA. A single histrelin implant is effective for 2 years for treatment of central precocious puberty. J Pediatr 2013;163:1214-6.

38. Swendiman RA, Vogiatzi MG, Alter CA, Nance ML. Histrelin implantation in the pediatric population: a 10-year institutional experience. J Pediatr Surg 2019;54:1457-61.

39. Klein KO, Soliman AM, Bonafede M, Nelson JK, Grubb E. Treatment patterns, health resource utilization and costs among central precocious puberty patients treated with leuprolide or histrelin: an examination of the commercial and Medicaid populations. J Med Econ 2020;23:407-14. 